\title{
Hepatoprotective effect of resveratrol against ethanol-induced oxidative stress through induction of superoxide dismutase in vivo and in vitro
}

\author{
WEI-MING CHEN ${ }^{1-3}$, LEE-HSIN SHAW ${ }^{4}$, PEY-JIUM CHANG ${ }^{2}$, SHUI-YI TUNG ${ }^{1,3}$, TE-SHENG CHANG ${ }^{1,2}$, \\ CHEIN-HENG SHEN ${ }^{1,2}$, YUNG-YU HSIEH ${ }^{1,3}$ and KUO-LIANG WEI ${ }^{1,3}$ \\ ${ }^{1}$ Division of Gastroenterology and Hepatology, Department of Internal Medicine, Chang Gung Memorial Hospital, \\ Puzi, Chiayi 61363; ${ }^{2}$ Graduate Institute of Clinical Medical Sciences; ${ }^{3}$ College of Medicine, Chang Gung University, \\ Taoyuan 333; ${ }^{4}$ Institute of Traditional Medicine, National Yang-Ming University, Taipei 11221, Taiwan, R.O.C.
}

Received May 28, 2015; Accepted December 1, 2015

DOI: $10.3892 /$ etm.2016.3077

\begin{abstract}
The present study aimed to investigate the hepatoprotective effect of resveratrol (RSV) against ethanol-induced oxidative stress in vivo, and investigate the underlying mechanisms by which RSV exerts its anti-oxidative effects on hepatic cells. C57BL/6J mice were divided into four groups: Untreated control, ethanol-treated, RSV-treated, and ethanol + RSV-treated. The plasma lipid profile, hepatic lipid accumulation and antioxidative enzyme activities were analyzed. HepG2 cells were used as a cellular model to analyze the effects of superoxide dismutase (SOD), catalase (CAT), glutathione peroxidase (GPx) and peroxisome proliferator-activated receptors (PPARs) in the RSV-mediated protection of ethanol-induced oxidative stress. In C57BL/6J mice, ethanol caused a significant increase in plasma triglyceride levels and hepatic lipid accumulation $(\mathrm{P}<0.05)$, whereas RSV notably increased SOD activity. In HepG2 cells, SOD activity was enhanced in the RSV-treated HepG2 cells, whereas the activity of CAT and GPx was not affected. Western blot and quantitative polymerase chain reaction analyses demonstrated that RSV significantly increased SOD protein and mRNA expression levels $(\mathrm{P}<0.05)$. Using a transient transfection assay, PPAR $\gamma$ was observed to participate in the regulation of SOD gene expression in RSV-administered HepG2 cells. To conclude, the results from the present study suggest that RSV may contribute towards the protection of hepatic cells from ethanol-induced oxidative stress via the induction of SOD activity and gene expression.
\end{abstract}

Correspondence to: Dr Kuo-Liang Wei, Division of Gastroenterology and Hepatology, Department of Internal Medicine, Chang Gung Memorial Hospital, 6 Section West, Chia-Po Road, Puzi, Chiayi 61363, Taiwan, R.O.C

E-mail: kuoliangwei@gmail.com

Key words: antioxidative enzyme, ethanol, oxidative stress, peroxisome proliferator-activated receptors, resveratrol

\section{Introduction}

Resveratrol (RSV; 3,5,4'-trihydroxystilbene) is a natural polyphenol found in grapes, red wine, peanuts and berries $(1,2)$. RSV possesses anti-oxidative and anti-inflammatory properties and is able to modulate lipid metabolism (3-7). Therefore, a diet rich in RSV may attenuate diabetes, and cardiovascular and stress-related diseases (8-11). The liver is the major organ responsible for metabolizing nutrients in the body and is easily damaged by an imbalance in redox status (12). However, the underlying mechanism by which RSV exerts its beneficial effects on hepatic damage remains unclear.

Alcoholic drinks are widely consumed throughout the world and have been implicated in many diseases such as liver cirrhosis and liver cancer, which globally account for an equal number of cases of mortality and disability as tobacco (13). The liver is the primary organ responsible for alcohol metabolism in the human body, and alcohol is primarily metabolized in hepatocytes. Reactive oxygen species (ROS) are known to cause ethanol-induced liver damage $(14,15)$, and a manifestation of alcoholic liver injury is lipid accumulation (16). Imbalanced lipid homeostasis, in addition to the generation of ROS, promotes the hepatic symptoms of steatosis, fibrosis, cirrhosis and hepatitis $(17,18)$. The antioxidative properties of RSV suggest that it may be a promising protective agent against alcoholic liver disease. In order to delineate the protective effect of RSV against oxidative damage in vivo, hepatic malondialdehyde (MDA, a lipid peroxidation product) levels and histopathology of the livers of ethanol plus RSV-treated mice were examined in the present study.

Endogenous antioxidative enzymes such as superoxide dismutase (SOD), catalase (CAT) and glutathione peroxidase (GPx) are able to protect the liver against oxidative damage (19). SOD scavenges the superoxide anion radical $\left(\mathrm{O}_{2}{ }^{\circ}\right)$ to oxygen and hydrogen peroxide $\left(\mathrm{H}_{2} \mathrm{O}_{2}\right) . \mathrm{H}_{2} \mathrm{O}_{2}$ may then be converted into water by CAT. By contrast, GPx is able to protect the cell against oxidative stress via the reduction of $\mathrm{H}_{2} \mathrm{O}_{2}$ and lipid peroxides, using glutathione as an electron donor (20). The present study provides an insight into the role of RSV in the regulation of antioxidative enzyme activity and 
gene expression, which contribute towards the defense mechanism against ROS in hepatocytes under oxidative stress.

Peroxisome proliferator-activated receptors (PPARs) are nuclear receptors that contribute towards nutrient-gene interactions, which are involved in the maintenance of metabolic homeostasis $(21,22)$. PPARs bind to retinoid-X receptors to form heterodimers and regulate the expression of their target genes, which have PPAR-response elements (PPREs) in their promoter regions (23). PPARs consist of 3 isoforms, namely PPAR $\alpha, \operatorname{PPAR} \beta / \delta$ and PPAR $\gamma$ (23). Among these PPARs, PPAR $\alpha$ is expressed at a relatively high concentration in the liver, where it oxidizes fatty acids and metabolizes lipids $(24,25)$. PPAR $\beta / \delta$ is involved in cell differentiation and epidermal wound healing (26-28). However, PPAR $\gamma$ regulates antioxidative enzyme genes, including SOD (29) and CAT (30). It has been suggested that PPAR $\gamma$ may serve an essential role in protecting organs against oxidative stress (31). The present study hypothesizes that RSV may display a modulatory role on PPARs in maintaining hepatic lipid homeostasis and in executing its antioxidative properties.

In the current study, the ability of RSV to modulate the activity of antioxidative enzymes in the mouse liver and in HepG2 cells was investigated. Furthermore, the effects of RSV on the expression of PPARs and the transcriptional activities of the reporter genes were evaluated using various PPREs in the 5'-upstream of the luciferase gene.

\section{Materials and methods}

Experimental animals. Thirty-two male C57BL/6J mice (6-8 weeks old, 18.5-20.3 g) were obtained from the Laboratory Animal Center of the National Yang Ming University (Taipei, Taiwan), and randomly assigned to one of four groups ( $n=8$ per group). Two animals were housed in each cage and maintained at $25^{\circ} \mathrm{C}$ in under a 12 -h light/dark cycle. All experimental procedures were approved by the Animal Care and Use Committee of the Chang Gung Medical Foundation (Chiayi, Taiwan) and complied with the NIH Guide for Care and Use of Laboratory Animals (National Research Council, 1996) (32). Mice in the four groups were administered daily, via oral gavage for 28 consecutive days, with the following: Ethanol (200 mg/kg); RSV (200 mg/kg; Sigma-Aldrich, St. Louis, MA, USA); ethanol + RSV (100 mg/kg each); or distilled water (control group). RSV was diluted in sterile water. Food and tap water were available ad libitum and body weight was recorded weekly throughout the experiment.

Following treatment, mice were anesthetized with $\mathrm{CO}_{2}$ and blood samples were extracted following a 12-h overnight fast. Plasma was isolated by centrifugation at $1,500 \mathrm{x}$ g for $15 \mathrm{~min}$ and was stored at $-35^{\circ} \mathrm{C}$ for subsequent biochemical analyses. Plasma concentrations of total cholesterol and triglycerol were determined spectrophotometrically using commercial kits (Merck Millipore, Darmstadt, Germany) according to manufacturer's instructions. The liver was rapidly removed, blotted dry, weighed, frozen in liquid nitrogen and stored at $-80^{\circ} \mathrm{C}$ until use. To analyze antioxidative enzyme activity and expression, the liver tissue was homogenized in 10 volumes of $50 \mathrm{mM}$ phosphate buffer ( $\mathrm{pH} 7.4$; Sigma-Aldrich) on ice using a Polytron homogenizer (model 099C-K54; Glas-Col LLC, Terre Haute, IN, USA). The homogenate was transferred into centrifuge tubes and centrifuged at $9,000 \times \mathrm{g}$ at $4{ }^{\circ} \mathrm{C}$ for $20 \mathrm{~min}$. The supernatant was separated for use in the subsequent measurement of antioxidative enzyme activity.

Measurement of MDA and hepatic lipid accumulation. Plasma levels of MDA, an oxidative stress marker, were monitored by quantifying thiobarbituric acid (TBA)-reactive substances as previously described (33). Briefly, $1 \mathrm{~g}$ liver tissue was homogenized in $10 \mathrm{ml} 1.15 \% \mathrm{KCl}$ buffer (Sigma-Aldrich). The homogenate was mixed with $1 \% \mathrm{H}_{3} \mathrm{PO}_{4}$ (Sigma-Aldrich) and $0.6 \%$ TBA (Sigma-Aldrich), and heated at $100^{\circ} \mathrm{C}$ for $45 \mathrm{~min}$. The samples were cooled to room temperature and combined with n-butanol (Merck Millipore). Following vigorous vortexing, the butanolic phase was centrifuged at 4,000 $\mathrm{x}$ g for 10 min. 1,1,3,3-Tetraethoxypropane (Merck Millipore) was used as the standard. The histology of hepatic microvesicular steatosis was assessed using the Oil Red O (Sigma-Aldrich) staining method as previously described (34).

Cell culture, cell viability and ROS assays. HepG2 is a well-differentiated human hepatocarcinoma cell line commonly used in hepatic studies. HepG2 cells were provided by Prof. An-Na Chiang and cultured in Dulbecco's Modified Eagle's Medium (HyClone; GE Healthcare, Logan, UT, USA) containing $10 \%$ fetal bovine serum, $100 \mathrm{U} / \mathrm{ml}$ penicillin, and $100 \mu \mathrm{g} / \mathrm{ml}$ streptomycin (GE Healthcare). After $24 \mathrm{~h}$ of growth at $37^{\circ} \mathrm{C}$ in $5 \% \mathrm{CO}_{2}$, cells were treated with ethanol or RSV $(50,100,200$ or $400 \mathrm{mM})$ for $24 \mathrm{~h}$. The 3-(4,5-dimethylthiazol-2-yl)-2,5-diphenyltetrazolium bromide (MTT) assay (Sigma-Aldrich) was used to evaluate the cytotoxic effects of ethanol and RSV (35). The ROS levels in HepG2 cells were measured using the dye, 2',7'-dichlorodihydrofluorescein diacetate (Molecular Probes; Thermo Fisher Scientific, Inc., Waltham, MA, USA), as described previously (36). This reduced dye was added to cells at a final concentration of $10 \mu \mathrm{M}$. The fluorescence of the oxidized dichlorofluorescein was recorded, with an excitation wavelength of $488 \mathrm{~nm}$ and an emission wavelength of $525 \mathrm{~nm}$, using flow cytometry (model FC500; Beckman Coulter, Inc., Brea, CA, USA). The results were expressed as the relative fluorescence intensity. Measurements of ROS levels without ethanol or RSV treatment were used as the control.

Measurement of antioxidative enzyme activity. SOD activity in the liver extracts of C57BL/6 mice or HepG2 cells was assayed using the hydroxylamine reduction method (37). The hypoxanthine/xanthine oxidase system (38) was used to measure the reduction of hydroxylamine by $\mathrm{O}_{2}{ }^{-}$, which was monitored at $550 \mathrm{~nm}$. One unit of SOD activity was recorded as the quantity of enzyme required to decrease the reduction of hydroxylamine by $50 \%$. Mouse liver or HepG2 cell CAT activity in the extract was assayed using the method described by Aebi (39). Decomposition of $\mathrm{H}_{2} \mathrm{O}_{2}$ resulting from CAT activity was assayed by monitoring $\mathrm{H}_{2} \mathrm{O}_{2}$ and the reduction in absorbance at $240 \mathrm{~nm}$. One unit of CAT activity was recorded as the quantity of enzyme catalyzing $1 \mu \mathrm{mol} \mathrm{H}_{2} \mathrm{O}_{2}$ per min at $25^{\circ} \mathrm{C}$. GPx activity was quantified according to a coupled enzyme (GPx and glutathione reductase) procedure (40), which measures the decrease in absorbance at $340 \mathrm{~nm}$ as NADPH is converted to NADP. One unit of GPx activity was recorded 
Table I. Effect of ethanol and resveratrol on plasma lipid profile and hepatic antioxidative enzyme activity in vivo.

\begin{tabular}{|c|c|c|c|c|}
\hline Parameter & Control & Ethanol & Resveratrol & Ethanol + resveratrol \\
\hline Body weight, $\mathrm{g}$ & $25.5 \pm 0.68$ & $26.1 \pm 0.58$ & $26.3 \pm 0.83$ & $25.9 \pm 0.66$ \\
\hline \multicolumn{5}{|l|}{ Plasma lipid } \\
\hline Total cholesterol, mg/dl & $96.4 \pm 10.3$ & $130 \pm 14.6$ & $121 \pm 12.8$ & $129 \pm 14.9$ \\
\hline Triglyceride, mg/dl & $81.0 \pm 10.8$ & $142 \pm 13.4^{\mathrm{a}}$ & $103 \pm 12.7$ & $122 \pm 15.4$ \\
\hline Malondialdehyde, $\mathrm{nmol} / \mathrm{l}$ & $254 \pm 30.4$ & $396 \pm 37.5^{\mathrm{a}}$ & $297 \pm 27.2$ & $333 \pm 41.2$ \\
\hline \multicolumn{5}{|l|}{ Hepatic antioxidative enzyme } \\
\hline Superoxide dismutase, $\mathrm{U} / \mathrm{mg}$ & $15.1 \pm 1.5$ & $18.7 \pm 2.2$ & $27.1 \pm 3.1^{\mathrm{a}}$ & $22.6 \pm 2.8$ \\
\hline Catalase, $\mathrm{U} / \mathrm{mg}$ & $42.1 \pm 4.8$ & $45.4 \pm 5.0$ & $47.8 \pm 4.7$ & $46.5 \pm 3.9$ \\
\hline Glutathione peroxidase, $\mathrm{mU} / \mathrm{mg}$ & $34.3 \pm 4.3$ & $39.5 \pm 4.1$ & $37.1 \pm 4.0$ & $38.9 \pm 4.4$ \\
\hline
\end{tabular}

Results are presented as the mean \pm standard error from four independent experiments. ${ }^{\mathrm{a}} \mathrm{P}<0.05 \mathrm{vs}$. control.

as the quantity of enzyme oxidizing $1 \mu \mathrm{mol}$ NADPH per min. The specific activity of SOD, CAT and GPx are expressed as $\mathrm{U} / \mathrm{mg}$ protein. The protein content of the liver or cell extract was determined using the Bradford method (Bio-Rad Laboratories, Inc., Hercules, CA, USA) (41).

Western blot analysis. Protein levels of antioxidative enzymes and PPARs were determined using western blot analysis in HepG2 cells supplemented with ethanol and/or RSV for $24 \mathrm{~h}$. Total cell protein was extracted using lysis buffer containing 1\% Triton X-100, 50 mM HEPES, 6 mM EDTA, and $150 \mathrm{mM} \mathrm{NaCl}$ supplemented with complete protease inhibitor cocktail (Roche Diagnostics GmbH, Mannheim, Germany). Cell lysates were centrifuged, and the supernatants were collected. The protein concentration was determined using the Bradford method (Bio-Rad Laboratories, Inc.) using bovine serum albumin as a standard, and equal quantities of protein $(30 \mu \mathrm{g})$ were analyzed by $10 \%$ sodium dodecyl sulfate polyacrylamide gel electrophoresis and transferred to nitrocellulose membranes (Pall Corporation, Port Washington, NY, USA). The immunoblots were blocked with $5 \%$ non-fat milk and then incubated at $4^{\circ} \mathrm{C}$ for $16-32 \mathrm{~h}$ with the following primary antibodies: Rabbit anti-human SOD polyclonal antibody (1:5,000; cat. no. ab13533; Abcam, Cambridge, UK); rabbit anti-human CAT polyclonal antibody (1:2,000; cat. no. ab16731; Abcam); goat anti-human GPx IgG (1:1,000; cat. no. sc-22145; Santa Cruz Biotechnology, Inc., Dallas, TX, USA); rabbit anti-human PPAR $\alpha$ IgG (1:1,000; cat. no. sc-9000; Santa Cruz Biotechnology, Inc.); rabbit anti-human PPAR $\beta / \delta$ IgG (1:1,000; cat. no. sc-7197; Santa Cruz Biotechnology, Inc.); goat anti-human PPAR $\gamma$ IgG (1:1,000; cat. no. sc-1981; Santa Cruz Biotechnology, Inc.). Following the washing stage, the blots were incubated with horseradish peroxidase-conjugated secondary antibodies (Sigma-Aldrich) for $1 \mathrm{~h}$ at $4^{\circ} \mathrm{C}$, and the target protein bands were visualized using Western Lightning Plus-Enhanced Chemiluminescence reagents (PerkinElmer, Inc., Waltham, MA, USA). The blots were then stripped for further probing, using $\beta$-actin (rabbit anti-human $\beta$-actin polyclonal antibody; cat. no. ab189073; Abcam) as an internal control. Relative intensities of protein bands were quantified by densitometry using ImageQuant software version 5.0 (Molecular Dynamics, Sunnyvale, CA, USA).

$R N A$ extraction and quantitative polymerase chain reaction (qPCR) analysis. Total RNA was extracted from HepG2 cells using TRIzol ${ }^{\circledR}$ reagent (Invitrogen; Thermo Fisher Scientific, Inc.) according to the manufacturer's instructions. Total RNA $(2 \mu \mathrm{g})$ was reverse transcribed using Moloney murine leukemia virus reverse transcriptase (Invitrogen; Thermo Fisher Scientific, Inc.). The resulting cDNA $(1 \mu \mathrm{g})$ was used as a template for qPCR analysis using SYBR Green Master Mixture (QuantiTect SYBR Green PCR kit 200; cat. no. 204143; Qiagen, Inc., Valencia, CA, USA) in a Roche LightCycler system (Roche Diagnostics GmbH). The specific primers (50 $\mu \mathrm{M}$ in $0.08 \mu \mathrm{l})$ for SOD, CAT and GPx genes were used as previously described (42). The following primer sequences were used: $\mathrm{Cu} / \mathrm{Zn}-\mathrm{SOD}$ forward, 5'-CAG GTCCTCACTTCAATCC-3' and reverse, 5'-CCAAACGAC TTCCAGCAT-3'; CAT forward, 5'-CGAAGGCGAAGG TGTTTG-3' and reverse, 5'-AGTGTGCGATCCATATCC-3'; GPx forward, 5'-CACAACGGTGCGGGACTA-3' and reverse, 5'-CATTGCGACACACTGGAGAC-3'; and glyceraldehyde-3-phosphate dehydrogenase (GAPDH) forward, 5'-GAAGGTGAAGGTCGGAGTC-3' and reverse, 5'-GAA GATGGTGATGGGATTTC-3'. Comparative assessment of target gene mRNA expression was performed using GAPDH mRNA as an internal control. Reaction conditions were $95^{\circ} \mathrm{C}$ for $10 \mathrm{~min}$, followed by 40 cycles of $95^{\circ} \mathrm{C}$ for $20 \mathrm{sec}, 60^{\circ} \mathrm{C}$ for $20 \mathrm{sec}$ and $72^{\circ} \mathrm{C}$ for $20 \mathrm{sec}$. Relative quantification of antioxidative enzyme mRNA was calculated using the $\mathrm{Cq}$ method (ratio $=2-(\mathrm{Cq}$ (antioxidant enzyme) $-\mathrm{Cq}(\mathrm{GAPDH})$ ) as described previously (43).

Transient transfection assays. HepG2 cells were transiently transfected with $0.2 \mu \mathrm{g}$ tk-PPREx-Luc reporter plasmid and $0.2 \mu \mathrm{g}$ PPAR $\alpha(\mathrm{pGShPPAR} \alpha), \operatorname{PPAR} \beta(\mathrm{pCMX}-\mathrm{hPPAR} \beta / \delta)$ or PPAR $\gamma$ (pCMX-hPPAR $\gamma$ ) expression vectors, which were constructed by Prof. An-Na Chiang's laboratory. For each transfection, the internal control vector, $\mathrm{pCMV}-\beta$-gal, was also co-transfected. The luciferase assay was measured using a luminometer (EG\&G Berthold; Berthold Technologies 

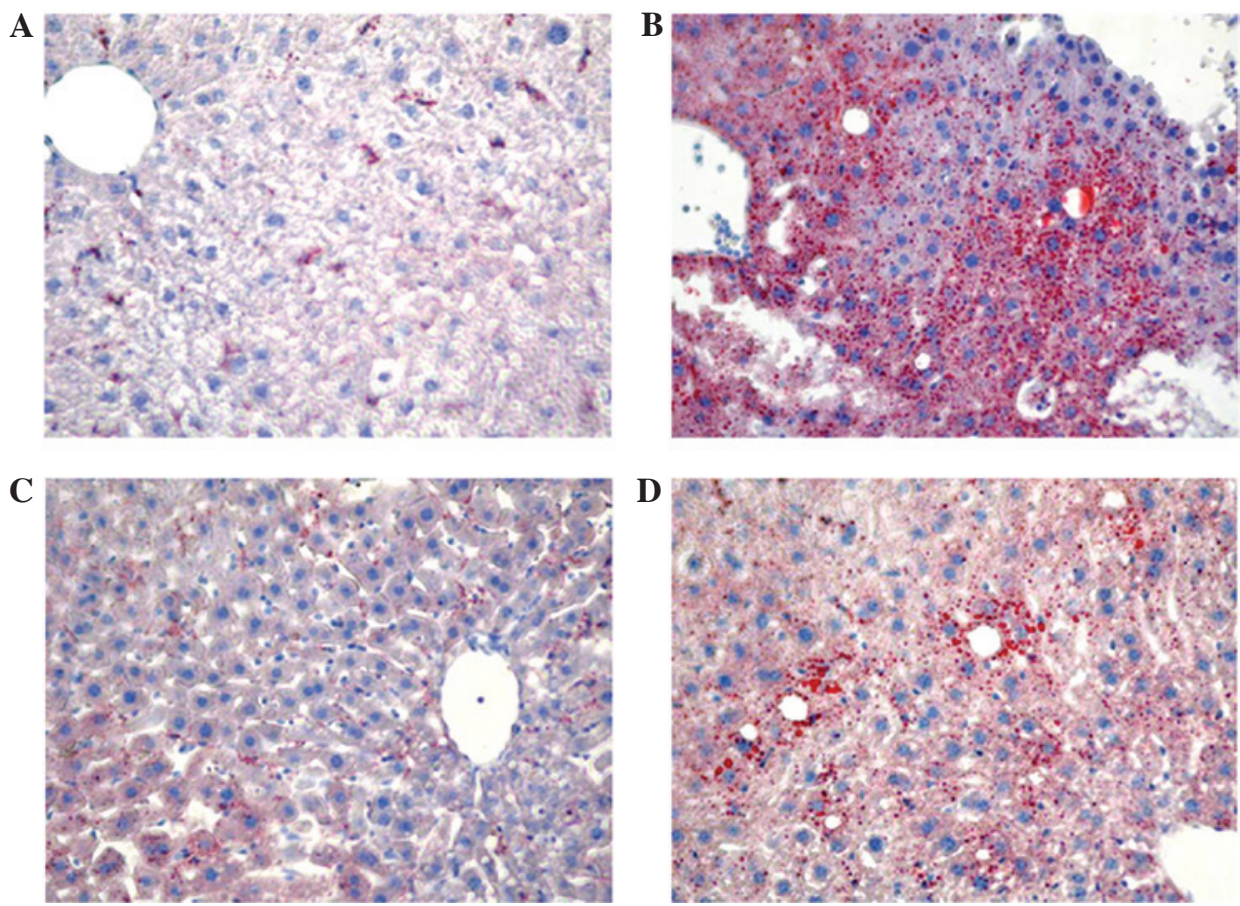

Figure 1. Representative photomicrographs of mice liver tissues in the (A) control, (B) ethanol, (C) resveratrol and (D) ethanol + resveratrol groups stained with Oil Red O (magnification, x200).

USA LLC, Oak Ridge, TN, USA) and normalized against the activity of $\beta$-galactosidase (44).

Statistical analysis. Data are presented as the mean \pm standard error. Each experiment was repeated at least three times. Statistical analysis between two groups was performed using the Student's t-test. One-way analysis of variance combined with Tukey's multiple-comparison test was used to evaluate the statistical significance of differences among the four groups. Statistical analysis was performed using SPSS software version 17.0 (SPSS, Inc., Chicago, IL, USA). P $<0.05$ was considered to indicate a statistically significant difference.

\section{Results}

Effect of ethanol and RSV on plasma lipid profile and hepatic antioxidative enzyme activity. Compared with the control mice, no significant differences were detected in the body weight and concentrations of plasma cholesterol levels among the groups (Table I). However, plasma triglyceride and MDA levels were 75.3 and $56.1 \%$ higher, respectively, in the ethanol-treated mice in comparison with the control mice (Table I). After 28 days of treatment, mice in the RSV group presented a $79.5 \%$ increase in SOD activity; however, no change was observed in the ethanol and ethanol + RSV groups. Moreover, ethanol and RSV exerted no significant effect on CAT and GPx activity compared with the control group in the livers of C57BL/6 mice. Furthermore, lipid accumulation was markedly increased in the liver of mice treated with ethanol, moderately increased in mice treated with ethanol + RSV and remained unchanged in mice treated with RSV (Fig. 1).

Effect of ethanol and RSV on cell viability and ROS production. No significant alteration of cell viability was detected by

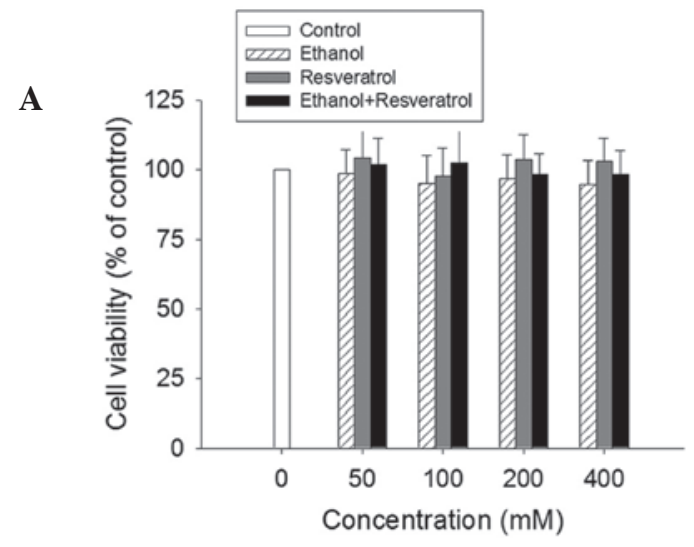

B

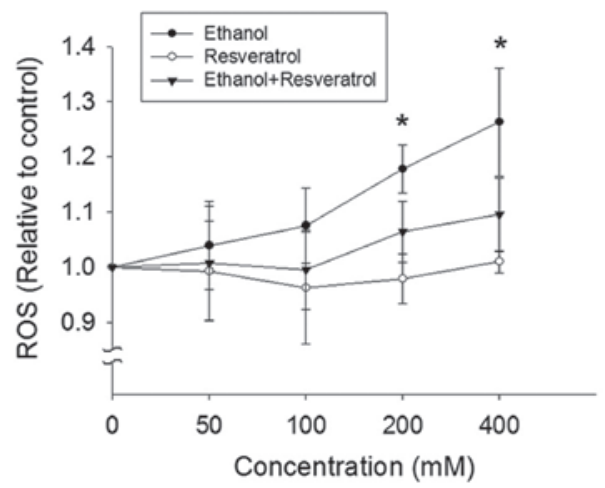

Figure 2. Effect of ethanol and resveratrol on cell viability and ROS production. (A) HepG2 cells were treated with 50, 100, 200 and $400 \mathrm{mM}$ ethanol, resveratrol, and ethanol plus resveratrol for $24 \mathrm{~h}$. The impact of resveratrol on cell viability was assessed using an MTT assay. All values are expressed as a percentage of the control group, which is set as $100 \%$. (B) ROS production was determined by the conversion of $2^{\prime}, 7^{\prime}$-dichlorodihydrofluorescein diacetate to $2^{\prime}, 7^{\prime}$-dichlorodihydrofluorescein. The results were expressed as the relative fluorescence intensity compared to the control, which is set as 1 . Data are presented as the mean \pm standard error $(n=3-5){ }^{*} \mathrm{P}<0.05$, vs. control. ROS, reactive oxygen species. 

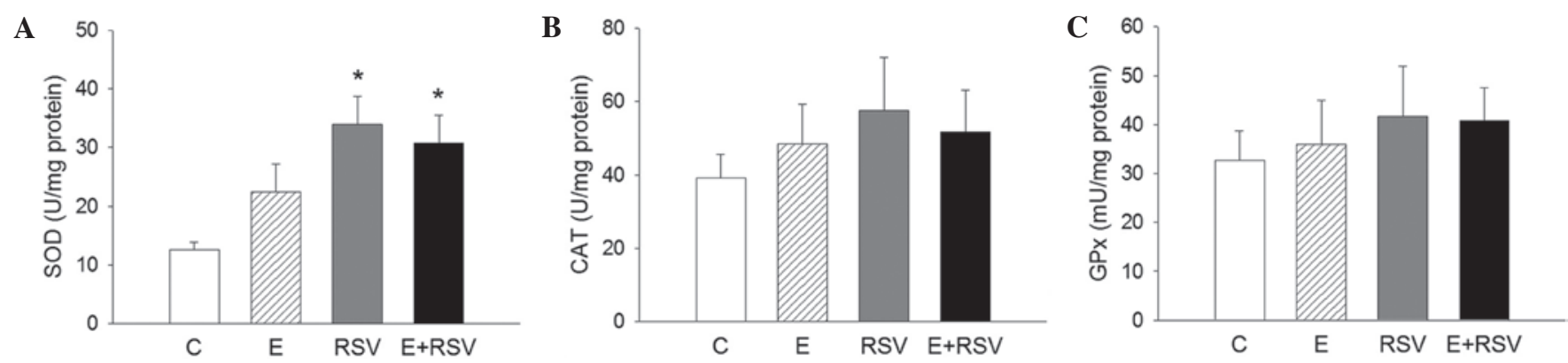

Figure 3. Effects of C, E and RSV on antioxidative enzyme activity. The enzyme activity of (A) SOD, (B) CAT and (C) GPx were analyzed. The results are representative of four different assays. Data are presented as the mean \pm standard error. ${ }^{~} \mathrm{P}<0.05$ vs. control. C, control; E, ethanol; RSV, resveratrol; SOD, superoxide dismutase; CAT, catalase; GPx, glutathione peroxidase.

A

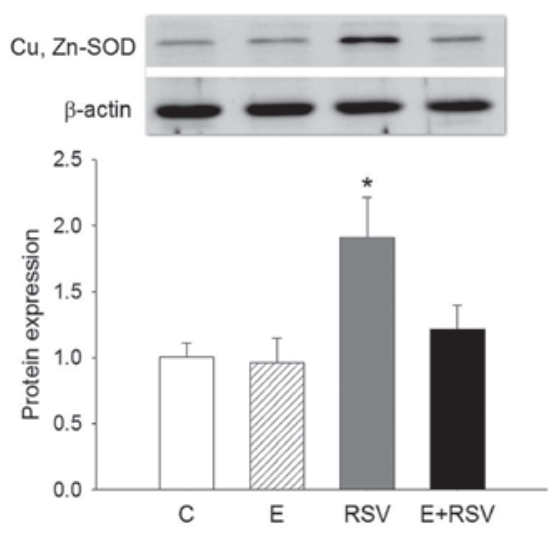

B

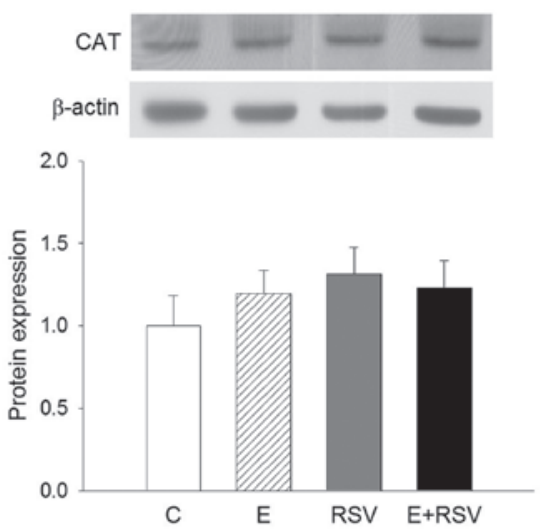

C



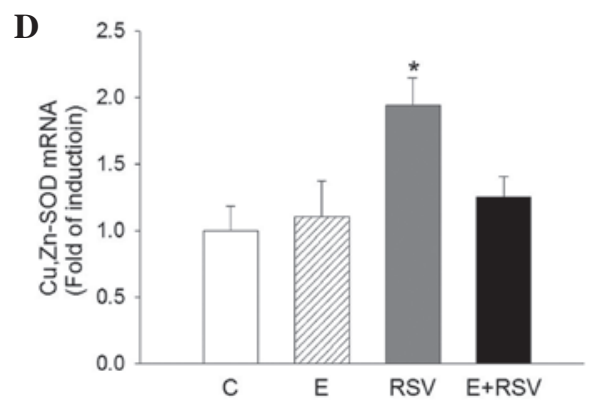


Figure 4. Effects of E and RSV on antioxidative enzyme mRNA and protein expression. Western blot and quantitative protein expression levels of (A) SOD, (B) CAT, and (C) GPx, and mRNA levels of (D) SOD, (E) CAT and (F) GPx were analyzed. The results are presented as the mean \pm standard error from four experiments. ${ }^{~} \mathrm{P}<0.05$ vs. control group. C, control; E, ethanol; RSV, resveratrol; SOD, superoxide dismutase; CAT, catalase; GPx, glutathione peroxidase.

the MTT assay in the HepG2 cells exposed to ethanol, RSV or ethanol + RSV (Fig. 2A). By contrast, ethanol treatment appeared to enhance ROS production in a dose-dependent manner (Fig. 2B). However, no significant change in ROS production was observed in the ethanol + RSV group. This indicates that RSV is able to scavenge ROS from ethanol-induced ROS generation.

Effect of ethanol and RSV on the activity and expression of antioxidative enzymes in HepG2 cells. To assess whether antioxidative enzymes are involved in RSV-mediated protection against oxidative stress, the activity of SOD, CAT and GPx was determined in HepG2 cells. As presented in Fig. 3, SOD activity significantly increased in cells exposed to RSV in comparison with the control $(\mathrm{P}<0.05)$, whereas the activity of CAT and GPx was not affected by ethanol or RSV treatment. The expression levels of SOD, CAT, and GPx protein (Fig. 4A-C) and mRNA (Fig. 4D-F) in HepG2 cells were determined by western blot and qPCR analysis. In comparison with the control cells, the expression levels of SOD protein and mRNA were 1.9- and 1.95-fold higher in the RSV group, respectively. There was no change in the expression of CAT and GPx in the three experimental groups in comparison with the control group.

Effect of ethanol and RSV on the protein transactivation activity of PPARs. To determine the mechanism underlying the induction of SOD gene expression by RSV, the expression and transactivation activity of PPARs in HepG2 cells was determined. PPAR $\alpha$, PPAR $\beta$ and PPAR $\gamma$ protein expression was not affected in cells treated with ethanol and/or RSV (Fig. 5A and B). However, the transfection of RSV-treated 




Figure 5. Effect of E and RSV on PPAR expression and activity. (A) Relative protein expression levels of PPAR $\alpha$, PPAR $\beta / \delta$, and PPAR $\gamma$ were measured using western blot analysis of nuclear extracts from HepG2 cells supplemented with ethanol and/or RSV for $24 \mathrm{~h}$. (B) The fold inductions of PPAR protein levels were expressed relative to the control, which is set as 1 . Data are presented as the mean \pm standard error $(n=4)$. (C) Transcriptional activity of PPAR $\alpha$, PPAR $\beta / \delta$, and PPAR $\gamma$ were evaluated by transfection assays using HepG2 cells with PPRE-luc together with pGSH PPAR $\alpha$, pCMX-hPPAR $\beta / \delta$ or pCMX-hPPAR $\gamma$ plasmids, respectively. Results are presented as the relative luciferase activity obtained by dividing normalized luciferase activity from the reporter vector PPRE-luc. ${ }^{*} \mathrm{P}<0.05$ vs. control cells $(\mathrm{n}=4)$. PPAR, proliferator-activated receptor; $\mathrm{C}$, control; E, ethanol; RSV, resveratrol.

HepG2 cells with the tk-PPRE $\gamma$-Luc reporter construct and pCMX-hPPAR $\gamma$ resulted in a 2.1 -fold increase in promoter activity in comparison with the untreated control cells (Fig. 5C). The treatment of HepG2 cells with $200 \mathrm{mM}$ ethanol alone or $100 \mathrm{mM}$ ethanol $+100 \mathrm{mM}$ RSV did not exert any significant effect on PPAR transactivation.

\section{Discussion}

Alcoholic drinks typically range between $\sim 4.5 \%$ ethanol (900 $\mathrm{mM}$ ) in beer and $\sim 12 \%$ ethanol (2 M) in wine (45). A large quantity of ingested ethanol circulates to the liver via the portal vein and creates a state of oxidative stress and lipid accumulation in hepatocytes $(14,46)$. In the present study, plasma triglyceride levels and MDA generation were increased in ethanol-treated mice, indicating that ethanol causes lipid metabolism disorder and increases lipid peroxidation in vivo. Oil Red O staining identified RSV-attenuated ethanol-induced lipid accumulation in the liver, which may be the cause or effect of ethanol on liver damage. The ethanol + RSV group had a lower accumulation of lipids in the liver compared with the ethanol treated group.

An imbalance of redox status may result in a wide range of health complications and various pathophysiological syndromes (47). Ethanol-induced oxidative stress causes liver damage in alcoholism (47). RSV, a widely used nutritional component, possesses various biological functions, including antioxidative effects (10). A previous study demonstrated that RSV inhibits foam cell formation via the suppression of ROS generation in macrophages (48). The present study aimed to determine whether RSV is able to prevent the ethanol-induced oxidative stress in hepatocytes.
An endogenous antioxidant system composed of antioxidative enzymes such as SOD, CAT and GPx, is responsible for the protection against free radical damage in vivo (49). The results of the present study suggest that the protective effect of RSV against ethanol-induced liver damage results from its ability to induce the activity of hepatic SOD. This was previously indicated in a study by Kasdallah-Grissa et al (50) who reported that the hepatic activity of SOD, CAT and GPX was suppressed in ethanol-treated rats, which was reversed by treatment with RSV. In the current study, the mechanisms underlying the protective action of RSV against oxidative stress, using HepG2 cells as the hepatic cellular model, were investigated. The results demonstrated that ethanol enhances ROS in a dose-dependent manner, and RSV protects cells against oxidative damage by suppressing ROS generation. Moreover, in the present study, RSV administration was demonstrated to enhance the activity and expression of SOD in comparison with the control group.

Previously, RSV has been observed to selectively activate PPARs in neuronal cells and adipocytes $(51,52)$. The SOD gene has known to be a PPAR $\gamma$ target gene (29). The present study hypothesized that RSV activates hepatic SOD gene expression through PPAR activation. The effect of RSV on PPAR expression and its transcriptional activation was investigated using western blot analysis and a luciferase assay. It was observed that RSV significantly upregulated PPAR $\gamma$ activity; however, its fundamental mechanism still remains to be elucidated.

In summary, the present study demonstrates that RSV serves an essential role in mitigating ethanol-induced hepatic oxidative stress in vivo and in vitro. This protective effect may result from the suppression of lipid peroxidation and accumulation, and the activation of SOD gene expression. 
Furthermore, it may be suggested that PPAR $\gamma$ activation is involved in RSV-enhanced SOD gene regulation. The results in the current study identify novel mechanisms underlying the protective actions of RSV and provide a novel insight into the prevention of ethanol-induced hepatic damage and liver disease.

\section{Acknowledgements}

The present study was supported by the Chang Gung Medical Foundation of Taiwan (grant no. CMRP:G6A0311). The authors thank Prof. An-Na Chiang (Institute of Biochemistry and Molecular Biology, National Yang-Ming University, Taipei, Taiwan) for providing HepG2 cells and technical assistance.

\section{References}

1. Pirola L and Fröjdö S: Resveratrol: One molecule, many targets. IUBMB Life 60: 323-332, 2008.

2. Shakibaei M, Harikumar KB and Aggarwal BB: Resveratrol addiction: To die or not to die. Mol Nutr Food Res 53: 115-128, 2009.

3. Leonard SS, Xia C, Jiang BH, Stinefelt B, Klandorf H, Harris GK and Shi X: Resveratrol scavenges reactive oxygen species and effects radical-induced cellular responses. Biochem Biophys Res Commun 309: 1017-1026, 2003.

4. Lasa A, Schweiger M, Kotzbeck P, Churruca I, Simón E, Zechner R and Portillo MP: Resveratrol regulates lipolysis via adipose triglyceride lipase. J Nutr Biochem 23: 379-384, 2012.

5. Mikuła-Pietrasik J, Kuczmarska A, Rubiś B, Filas V, Murias M, Zieliński P, Piwocka K and Książek K: Resveratrol delays replicative senescence of human mesothelial cells via mobilization of antioxidative and DNA repair mechanisms. Free Radic Biol Med 52: 2234-2245, 2012

6. Park DW, Kim JS, Chin BR and Baek SH: Resveratrol inhibits inflammation induced by heat-killed Listeria monocytogenes J Med Food 15: 788-794, 2012.

7. Voloshyna I, Hussaini SM and Reiss AB: Resveratrol in cholesterol metabolism and atherosclerosis. J Med Food 15: 763-773, 2012

8. Bhatt JK, Thomas S and Nanjan MJ: Resveratrol supplementation improves glycemic control in type 2 diabetes mellitus. Nutr Res 32: 537-541, 2012.

9. Chang CC, Chang CY, Huang JP and Hung LM: Effect of resveratrol on oxidative and inflammatory stress in liver and spleen of streptozotocin-induced type 1 diabetic rats. Chin J Physiol 55: 192-201, 2012

10. Sadruddin S and Arora R: Resveratrol: Biologic and therapeutic implications. J Cardiometab Syndr 4: 102-106, 2009.

11. Tomé-Carneiro J, Gonzálvez M, Larrosa M, García-Almagro FJ, Avilés-Plaza F, Parra S, Yáñez-Gascón MJ, Ruiz-Ros JA, García-Conesa MT, Tomás-Barberán FA and Espín JC: Consumption of a grape extract supplement containing resveratrol decreases oxidized LDL and ApoB in patients undergoing primary prevention of cardiovascular disease: A triple-blind 6-month follow-up, placebo-controlled, randomized trial. Mol Nutr Food Res 56: 810-821, 2012.

12. Cesaratto L, Vascotto C, Calligaris S and Tell G: The importance of redox state in liver damage. Ann Hepatol 3: 86-92, 2004.

13. Room R, Babor T and Rehm J: Alcohol and public health. Lancet 365: 519-530, 2005.

14. Cahill A, Cunningham CC, Adachi M, Ishii H, Bailey SM, Fromenty B and Davies A: Effects of alcohol and oxidative stress on liver pathology: The role of the mitochondrion. Alcohol Clin Exp Res 26: 907-915, 2002.

15. Hoek JB and Pastorino JG: Cellular signaling mechanisms in alcohol-induced liver damage. Semin Liver Dis 24: 257-272, 2004

16. Wu KC, Liu J and Klaassen CD: Role of Nrf2 in preventing ethanol-induced oxidative stress and lipid accumulation. Toxicol Appl Pharmacol 262: 321-329, 2012.

17. de Alwis NM and Day CP: Non-alcoholic fatty liver disease: The mist gradually clears. J Hepatol 48 (Suppl 1): S104-S112, 2008

18. Mann RE, Smart RG and Govoni R: The epidemiology of alcoholic liver disease. Alcohol Res Health 27: 209-219, 2003.
19. Kumar M, Sharma VL, Sehgal A and Jain M: Protective effects of green and white tea against benzo(a)pyrene induced oxidative stress and DNA damage in murine model. Nutr Cancer 64 300-306, 2012

20. Pigeolet E, Corbisier P, Houbion A, Lambert D, Michiels C, Raes M, Zachary MD and Remacle J: Glutathione peroxidase, superoxide dismutase, and catalase inactivation by peroxides and oxygen derived free radicals. Mech Ageing Dev 3: 283-297, 1990.

21. Jonker JW, Suh JM, Atkins AR, Ahmadian M, Li P, Whyte J, He M, Juguilon H, Yin YQ, Phillips CT, et al: A PPAR $\gamma$-FGF1 axis is required for adaptive adipose remodelling and metabolic homeostasis. Nature 485: 391-394, 2012.

22. Kidani Y and Bensinger SJ: Liver X receptor and peroxisome proliferator-activated receptor as integrators of lipid homeostasis and immunity. Immunol Rev 249: 72-83, 2012.

23. Berger J and Moller DE: The mechanisms of action of PPARs. Annu Rev Med 53: 409-435, 2002.

24. Huang J, Jia Y, Fu T, Viswakarma N, Bai L, Rao MS, Zhu Y, Borensztajn J and Reddy JK: Sustained activation of PPAR $\alpha$ by endogenous ligands increases hepatic fatty acid oxidation and prevents obesity in ob/ob mice. FASEB J 26: 628-638, 2012.

25. Takahashi N, Senda M, Lin S, Goto T, Yano M, Sasaki T, Murakami S and Kawada T: Auraptene regulates gene expression involved in lipid metabolism through PPAR $\alpha$ activation in diabetic obese mice. Mol Nutr Food Res 55: 1791-1797, 2011.

26. Chong HC, Tan MJ, Philippe V, Tan SH, Tan CK, Ku CW, Goh YY, Wahli W, Michalik L and Tan NS: Regulation of epithelial-mesenchymal IL-1 signaling by PPARbeta/delta is essential for skin homeostasis and wound healing. J Cell Biol 184: 817-831, 2009.

27. Man MQ, Barish GD, Schmuth M, Crumrine D, Barak Y, Chang S, Jiang Y, Evans RM, Elias PM and Feingold KR: Deficiency of PPARbeta/delta in the epidermis results in defective cutaneous permeability barrier homeostasis and increased inflammation. J Invest Dermatol 128: 370-377, 2008

28. Müller R, Rieck M and Müller-Brüsselbach S: Regulation of cell proliferation and differentiation by PPAR $\beta / \delta$. PPAR Res 2008 : 614852, 2008.

29. Yoo HY, Chang MS and Rho HM: Induction of the rat $\mathrm{Cu} / \mathrm{Zn}$ superoxide dismutase gene through the peroxisome proliferator-responsive element by arachidonic acid. Gene 234: 87-91, 1999

30. Girnun GD, Domann FE, Moore SA and Robbins ME: Identification of a functional peroxisome proliferator-activated receptor response element in the rat catalase promoter. Mol Endocrinol 16: 2793-2801, 2002.

31. Jung KH, Chu K, Lee ST, Kim SJ, Song EC, Kim EH, Park DK, Sinn DI, Kim JM, Kim M and Roh JK: Blockade of AT1 receptor reduces apoptosis, inflammation, and oxidative stress in normotensive rats with intracerebral hemorrhage. J Pharmacol Exp Ther 322: 1051-1058, 2007.

32. National Research Council (US) Institute for Laboratory Animal Research: Guide for the Care and Use of Laboratory Animals. Washington (DC): National Academies Press (US), 1996.

33. Lin KY, Chen YL, Shih CC, Pan JP, Chan WE and Chiang AN: Contribution of HDL-apolipoproteins to the inhibition of low density lipoprotein oxidation and lipid accumulation in macrophages. J Cell Biochem 86: 258-267, 2002.

34. Cui W, Chen SL and Hu KQ: Quantification and mechanisms of oleic acid-induced steatosis in HepG2 cells. Am J Transl Res 2: 95-104, 2010.

35. Carmichael J, DeGraff WG, Gazdar AF, Minna JD and Mitchell JB: Evaluation of a tetrazolium-based semiautomated colorimetric assay: Assessment of chemosensitivity testing. Cancer Res 47: 936-942, 1987.

36. LeBel CP, Ischiropoulos $\mathrm{H}$ and Bondy SC: Evaluation of the probe 2',7'-dichlorofluorescin as an indicator of reactive oxygen species formation and oxidative stress. Chem Res Toxicol 5: 227-231, 1992

37. Oyanagui Y: Reevaluation of assay methods and establishment of kit for superoxide dismutase activity. Anal Biochem 142: 290-296, 1984

38. Chen J, Rogers SC and Kavdia M: Analysis of kinetics of dihydroethidium fluorescence with superoxide using xanthine oxidase and hypoxanthine assay. Ann Biomed Eng 41: 327-337, 2013.

39. Aebi H: Catalase in vitro. Methods Enzymol 105: 121-126, 1984.

40. Flohé L and Günzler WA: Assays of glutathione peroxidase. Methods Enzymol 105: 114-121,1984. 
41. Bradford MM: A Rapid and sensitive method for the quantitation of microgram quantities of protein utilizing the principle of protein-dye binding. Anal Biochem 72: 248-254, 1976.

42. Xu CL, Wang YZ, Guo J, Liu JX and Feng J: Comparison of age-related differences in expression of antioxidant enzyme mRNA and activity in various tissues of pigs. Comp Biochem Physiol B Biochem Mol Biol 147: 445-451, 2007.

43. Patel DN, King CA, Bailey SR, Holt JW, Venkatachalam K, Agrawal A, Valente AJ and Chandrasekar B: Interleukin-17 stimulates C-reactive protein expression in hepatocytes and smooth muscle cells via p38 MAPK and ERK1/2-dependent NF-kappaB and C/EBPbeta activation. J Biol Chem 282: 27229-27238, 2007.

44. Young DC, Kingsley SD, Ryan KA and Dutko FJ: Selective inactivation of eukaryotic $\beta$-galactosidase in assays for inhibitors of HIV-1 TAT using bacterial $\beta$-galactosidase as a reporter enzyme. Anal Biochem 215: 24-30, 1993.

45. Pochareddy S and Edenberg HJ: Chronic alcohol exposure alters gene expression in HepG2 cells. Alcohol Clin Exp Res 36: 1021-1033, 2012.

46. Tsukamoto $\mathrm{H}$ and Lu SC: Current concepts in the pathogenesis of alcoholic liver injury. FASEB J 15: 1335-1349, 2001.
47. Comporti M, Signorini C, Leoncini S, Gardi C, Ciccoli L, Giardini A, Vecchio D and Arezzini B: Ethanol-induced oxidative stress: Basic knowledge. Genes Nutr 2: 101-109, 2010.

48. Park DW, Baek K, Kim JR, Lee JJ, Ryu SH, Chin BR and Baek SH: Resveratrol inhibits foam cell formation via NADPH oxidase 1-mediated reactive oxygen species and monocyte chemotactic protein-1. Exp Mol Med 41: 171-179, 2009.

49. Matés JM, Pérez-Gómez C and Núñez de Castro I: Antioxidant enzymes and human diseases. Clin Biochem 32: 595-603, 1999.

50. Kasdallah-Grissa A, Mornagui B, Aouani E, Hammami M, El May M, Gharbi N, Kamoun A and El-Fazaâ S: Resveratrol, a red wine polyphenol, attenuates ethanol-induced oxidative stress in rat liver. Life Sci 80: 1033-1039, 2007.

51. Cheng G, Zhang X, Gao D, Jiang X and Dong W: Resveratrol inhibits MMP-9 expression by up-regulating PPAR alpha expression in an oxygen glucose deprivation-exposed neuron model. Neurosci Lett 451: 105-108, 2009.

52. Kennedy A, Overman A, Lapoint K, Hopkins R, West T, Chuang CC, Martinez K, Bell D and McIntosh M: Conjugated linoleic acid-mediated inflammation and insulin resistance in human adipocytes are attenuated by resveratrol. J Lipid Res 50: 225-232, 2009 . 